\title{
Toxicogenomics in non-mammalian species-Editorial
}

\author{
Stephen Stürzenbaum ${ }^{1 *}$, Michael Aschner ${ }^{2}$ and Jonathan H. Freedman ${ }^{3}$ \\ ${ }_{1}^{1}$ Analytical and Environmental Science Division, School of Biomedical Sciences, King's College London, London, UK \\ ${ }^{2}$ Vanderbilt University Medical Center, Nashville, TN, USA \\ ${ }^{3}$ Laboratory of Toxicology and Pharmacology, National Institute of Environmental Health Science, National Institute of Health, \\ Research Triangle Park, NC, USA \\ *Correspondence: stephen.sturzenbaum@kcl.ac.uk
}

Edited by:

Douglas M. Ruden, Wayne State University, USA

Reviewed by:

Douglas M. Ruden, Wayne State University, USA

In October 2004, the Organisation for Economic Co-operation and Development (OECD) and the International Programme on Chemical Safety (IPCS) organized a workshop in Kyoto Japan to outline the fundamental aspects and future directions of the then emerging science of "Toxicogenomics." The output of this three-day meeting was summarized in the Report of the OECD/IPCS workshop on Toxicogenomics (OECD Series on Testing and Assessment, Number 50, http://www.who. int/ipcs/methods/oecd_report.pdf). In essence, Toxicogenomics was defined as any study that investigates the response of a genome to hazardous substances by means of (1) genomicscale mRNA expression analyses (Transcriptomics), (2) cell and tissue wide protein expression techniques (Proteomics), or (3) cell and tissue wide metabolite profiling (Metabolomics). These "omic" datasets typically require intricate in silico analyses (Bioinformatics) to integrate the results and by doing so provide insights into mechanistic toxicology and biomarkers of exposure.

Since 2004, the initiation, and indeed completion, of numerous whole genome-sequencing projects has driven the exponential growth of available genetic information. Collating this vast amount of data into functional and mechanistically meaningful units is providing novel insights into pathogenesis, new methods of risk assessment, genetic risk-modifications in preventative medicine, and new therapeutic targets for pharmaceutical and biological medicines. Most toxicogenomic responses, however, are multi-dimensional due to the facts that toxicants usual affect multiple intra-and extra-cellular targets and occur as complex mixtures, which are inherently difficult to decipher. Some molecules or conditions are exclusively toxic to biological systems and classified as being non-essential, while others are essential for life. According to Paracelsus, above certain threshold even the essential will become toxic. Thus, tightly controlled homeostatic control mechanisms are vital drivers of well-being, longevity, and survival. The identification and characterization of these mechanisms and the cognate regulatory pathways form the foundations of Toxicogenomics.

This Research Topic issue explores our current knowledge pertaining to the multitude of genomic and toxicological tools within non-mammalian organisms, arguably an underdeveloped niche. This e-book begins with five seminal reviews on (1) the yeast system, which focusses on genome-wide responses to chemical stressors linked to Environmental Health, Pharmacology, and Biotechnology (dos Santos et al., 2012); (2) the fruit fly Drosophila melanogaster, as a model for lead neurotoxicology and Toxicogenomics (Hirsch et al., 2012); (3) the nematode Caenorhabditis elegans, to investigate the genome-wide response to metal exposure (Caito et al., 2012); (4) next generation sequencing approaches in fish Toxicogenomics (Mehinto et al., 2012); and (5) the application of Toxicogenomics in amphibians (Helbing, 2012). These reviews set the stage for five research articles that describe how genomic tools have aided in uncovering target mechanisms of (eco)toxicological importance. These comprise transcript meta-analyses in C. elegans to pinpoint humic acid, quercetin, and tannic acid-mediated effectors of stress and aging (Pietsch et al., 2012 and Menzel et al., 2012); the assessment of a municipal landfill soil via a functional environmental genomic approach using the springtail Folsomia candida (Roelofs et al., 2012); a bioinformatic approach to model genotoxic chemical mutations in Drosophila melanogaster (Cingolani et al., 2012); and a study that investigates the influence of nitrate and nitrite on targeted gene expression in the tadpole Rana catesbeiana (Hinther et al., 2012).

By spanning a wide taxonomic breadth, this encyclopaedic coverage results in a collection of unique approaches, tools and technologies, which are currently defined by the availability and feasibility for each organism to study the genomics of xenobiotic or stress biology. We anticipate that this information will not only foster cross-phyla awareness, but also expand the horizon of Toxicogenomics. We hope you enjoy this eclectic mix of papers. 


\section{REFERENCES}

Caito, S., Fretham, S., Martinez-Finley, E., Chakraborty, S., Avila, D., Chen, P., et al. (2012). Genome-wide analyses of metal responsive genes in Caenorhabditis elegans. Front. Gene. 3:52. doi: 10.3389/fgene.2012. 00052

Cingolani, P., Patel, V. M., Coon, M., Nguyen, T., Land, S. J., Ruden, D. M., et al. (2012). Using Drosophila melanogaster as a model for genotoxic chemical mutational studies with a new program, SnpSift. Front. Gene. 3:35. doi: 10.3389/fgene.2012.00035

dos Santos, S. C., Teixeira, M. C., Cabrito, T. R., and Sá-Correia, I. (2012). Yeast toxicogenomics: genome-wide responses to chemical stresses with impact in environmental health, pharmacology, and biotechnology. Front. Gene. 3:63. doi: 10.3389/fgene.2012.00063
Helbing, C. C. (2012). The metamorphosis of amphibian toxicogenomics. Front. Gene. 3:37. doi: 10.3389/fgene.2012.00037

Hinther, A., Edwards, T. M., Guillette, Jr. L. J., and Helbing, C. C. (2012). Influence of nitrate and nitrite on thyroid hormone responsive and stress-associated gene expression in cultured Rana catesbeiana tadpole tail fin tissue. Front. Gene. 3:51. doi: 10.3389/fgene.2012.00051

Hirsch, H. V. B., Lnenicka, G., Possidente, D., Possidente, B., Garfinkel, M. D., Wang, L., et al. (2012). Drosophila melanogaster as a model for lead neurotoxicology and toxicogenomics research. Front. Gene. 3:68. doi: 10.3389/fgene.2012.00068

Mehinto, A. C., Martyniuk, C. J., Spade, D. J., and Denslow, N. D. (2012). Applications of next-generation sequencing in fish ecotoxicogenomics. Front. Gene. 3:62. doi: 10.3389/fgene.2012.00062

Menzel, R., Menzel, S., Swain, S. C., Pietsch, K., Tiedt, S., Witczak, J., et al. (2012). The nematode Caenorhabditis elegans, stress and aging: identifying the complex interplay of genetic pathways following the treatment with humic substances. Front. Gene. 3:50. doi: 10.3389/fgene.2012.00050

Pietsch, K., Saul, N., Swain, S. C., Menzel, R., Steinberg, C. E. W. and Stürzenbaum, S. R. (2012). Meta-analysis of global transcriptomics suggests that conserved genetic pathways are responsible for Quercetin and Tannic acid mediated longevity in C. elegans. Front. Gene. 3:48. doi: 10.3389/fgene.2012.00048

Roelofs, D., de Boer, M., Agamennone, V., Bouchier, P., Legler, J., and van Straalen, N. (2012). Functional environmental genomics of a municipal landfill soil. Front. Gene. 3:85. doi: 10.3389/fgene.2012.00085

Received: 28 September 2012; accepted: 28 September 2012; published online: 16 October 2012.

Citation: Stürzenbaum S, Aschner $M$ and Freedman JH (2012) Toxicogenomics in non-mammalian species-Editorial. Front. Gene. 3:216. doi: 10.3389/fgene.2012.00216

This article was submitted to Frontiers in Toxicogenomics, a specialty of Frontiers in Genetics.

Copyright (c) 2012 Stürzenbaum, Aschner and Freedman. This is an open-access article distributed under the terms of the Creative Commons Attribution License, which permits use, distribution and reproduction in other forums, provided the original authors and source are credited and subject to any copyright notices concerning any third-party graphics etc. 